\title{
Construction of Wendelstein 7-X - engineering a steady state stellarator
}

\author{
H.-S. Bosch, V. Erckmann, R. König, F. Schauer, R. Stadler, A. Werner, Wendelstein 7-X Team \\ Max-Planck-Institut für Plasmaphysik, IPP-Euratom Association \\ D-17491 Greifswald, Germany \\ Bosch@ipp.mpg.de
}

\begin{abstract}
The next step in the Wendelstein stellarator line is the large superconducting device Wendelstein $7-X$, presently under construction in Greifswald. Steady-state operation is an intrinsic feature of stellarators, and one key element of the Wendelstein 7-X mission is to demonstrate steady-state operation at reactor relevant plasma conditions, as required for an economic fusion reactor. Such steady-state operation requires development of special technogies to be discussed in this paper.
\end{abstract}

Keywords: Wendelstein 7-X, optimized stellarator, construction, steady-state operation

\section{INTRODUCTION}

Wendelstein 7-X (W7-X), presently under construction in the IPP branch-institute in Greifswald, is a fully optimized stellarator [1]. Its optimisation is based on the concept of quasiisodynamicity [2]. The criteria to select the final magnetic configuration have been the following:

- $\quad$ high quality vacuum magnetic surfaces

- $\quad$ good finite- $\beta$ equilibrium properties

- $\quad$ good MHD stability properties

- $\quad$ small neoclassical transport in the "long mean free path (lmfp) regime"

- $\quad$ small bootstrap fraction in the $1 \mathrm{mfp}$ regime

- $\quad$ good collisionless alpha particle containment

- fabrication feasibility of modular coils.

The W7-X configuration has a five-fold symmetry and is described by a rotational transform $1 / 2 \pi$ of about $1(0.72<1 / 2 \pi$ $<1.25$ ) with low shear (i.e. a small variation of $1 / 2 \pi$ across the magnetic surfaces). The major radius of the plasma is $5.5 \mathrm{~m}$, the effective (i.e. averaged) minor radius is $0.55 \mathrm{~m}$, and the magnetic axis is helical.

The top part of Fig. 1 shows the $3 d$-shaped toroidal plasma (toroidally varying poloidal cross-section) with a part of the coil system producing the corresponding confining magnetic field. Clearly visible is the pentagon-shape of the torus. The actual device can therefore be set-up from five identical modules. Each of those is made out of two flip-symmetric parts, so that in fact the device is composed of 10 almost identical half-modules. A schematic view of the basic device with its main components [3] is shown in the bottom part of Fig. 1.
In the first stage of its operation, Wendelstein 7-X will have
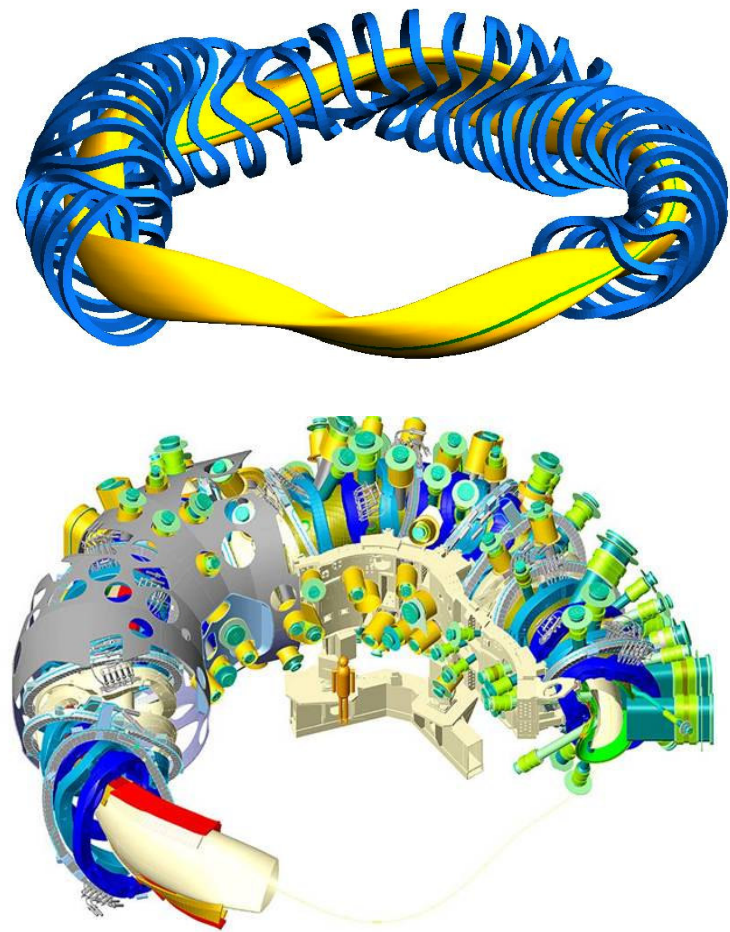

Figure 1: Top: Schematic view of the toroidal plasma (yellow) with a part of the 50 non-planar coils. Bottom: Cutaway of a CAD drawing of W7-X showing the plasma and the divertor plates (lower left), the magnetic coils around the plasma vessel with inner support structure (upper right) and the Outer Vessel (upper left).

to prove the good confinement properties predicted by the numerical optimization, i.e. confinement in the range of that seen in tokamaks of comparable size. Beyond that, however, a key element of the Wendelstein 7-X mission is to demonstrate steady-state operation at reactor relevant plasma conditions, as required for an economic fusion reactor. Steady-state operation is an intrinsic feature of stellarators, unlike tokamaks, where steady state operation is still a major challenge that requires extensive research and development effort.

But independently of the confinement scheme, steady-state operation of fusion relevant plasmas is a complex task that is composed of both engineering and physics issues. 
In this paper, the construction status of Wendelstein 7-X will be discussed with special emphasis on the engineering issues of a steady state fusion device. The main components which require special engineering to become ready for steadystate operation will be discussed in the next chapter. Chapter III will then treat the status of device assembly.

\section{II. “STEADY-STATE” COMPONENTS OF WENDELSTEIN 7-X}

\section{A. Magnetic coil system}

\section{1) Superconducting coils}

For the magnet system, the requirement of steady-state operation simply means the use of superconducting coils. This also results in the need to have a superconductive bus-bar system to connect the coils with each other, current leads (CL) as transitions from the cold conductors to the room temperature bus bars and power supplies, and operation of a cryo plant.

The W7-X magnet system is made from 50 non-planar coils of 5 different types which set up the basic confining field, and from 20 planar coils (2 different types) which allow for a variation of the magnetic field configuration.

The non-planar coils (see Fig. 2) have been manufactured by a German-Italian consortium of Babcock Noell and Ansaldo Supercoductors [4]. The winding pack contains 108 windings of a NbTi cable within an Al-alloy conduit which allows $\mathrm{He}$ cooling through the voids between the strands of the cable. Actually, for one non-planar coil six lengths of the conductor have to be used, connected in series by low resistance joints $(<$ $1 \mathrm{n} \Omega$ ) which are also used as supercritical He inlet/outlet for the superconductor cooling. The electrical insulation in this region, i.e. at the exit of the cables from the winding pack and around the interlayer joints, has turned out to be an especially difficult area. Paschen tests, i.e. high voltage tests at different vacuum pressure levels, have proven to be a very effective tool for testing the quality of this insulation [5] and for unveiling problematic areas. The winding packs are embedded in cast steel casings to withstand the large electromagnetic forces resulting from the $3 \mathrm{~d}$-shape.

As of now, all 50 non-planar coils have been delivered. 49 of them have already been tested individually at CEA in Saclay/France. These cryogenic tests in full-current operation are part of the final acceptance test and have proven the expected properties for all non-planar coils [6].

The 20 planar coils, supplied by Tesla in the UK, have casings that are made from two vertical rings and top and bottom plates bolted to them [7]. As of today, all 20 coils have already successfully completed the cryogenic tests in Saclay.

\section{2) Magnet support system}

All superconducting coils will be fixed to a central support ring (CSR). This structure is made up of 10 identical, welded segments which are bolted together to form a pentagon-shaped ring of 5 modules. Casted steel extensions for holding the coils are welded to this ring [8]. As the coils have to be kept in their precise position, also during cool down and operation, these fixtures have to be very rigid. The connection surfaces (flanges) on these extensions as well as on the coils have to be machined to a high accuracy of a few tenth of a millimeter. 8 out of the 10 support ring half-modules have been delivered already, and the last two half-modules are in the final stage of fabrication. The support ring will be carried by 10 cryosupports which also provide the thermal barrier to the machine base in the torus hall.

Each of the 70 coils is fixed radially to the support ring in two points, where the magnetic forces (up to $4.4 \mathrm{MN}$ ) and bending moments (up to $450 \mathrm{kNm}$ ) have to be taken up. To keep the coils firmly but elastically in place, a bolted solution has been developed that uses long and slender Inconel bolts and sleeves which even allow slight opening of the flanges for reduction of stresses [9].

Large electro-magnetic forces act also between the nonplanar coils. Therefore, they have to be supported against each other with a system that can take up the forces and moments and keep their positions to a high accuracy. On the inner side of the torus, where the distance between coils is rather small (a few $\mathrm{cm}$ ) and accessibility is limited, so-called Narrow Support Elements (NSE, see [10]) are foreseen. These are gliding elements that can take up contact forces up to $1.5 \mathrm{MN}$, sliding distances of up to $5 \mathrm{~mm}$, and tilting up to 1 degree during magnet energization. On the outboard side of the torus, socalled Lateral Support Elements (LSE) are installed. These LSE provide a rigid connection, generally made of half-boxes which are welded between the neighboring coils. The crucial issue here is the proper control of welding shrinkage and distortion which is essential to comply with the magnet system assembly tolerances. An extensive test program has been carried out to optimize the layout and welding procedures for these elements. The LSE between the modules is a bolted inconel "bridge" which posed quite a design challenge.

\section{3) Bus-bar system and current leads}

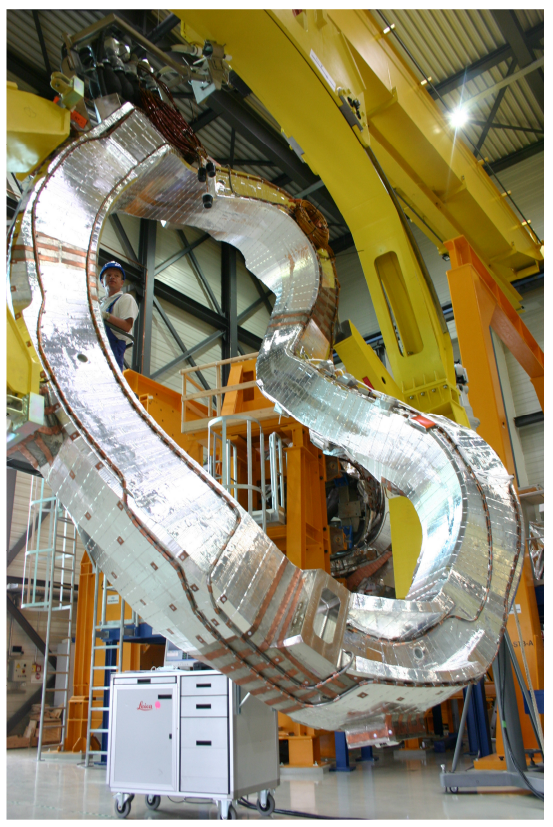

Figure 2: A non-planar coil, ready for assembly onto the plasma vessel. The coil is fixed in the assembly handler unit (yellow). 


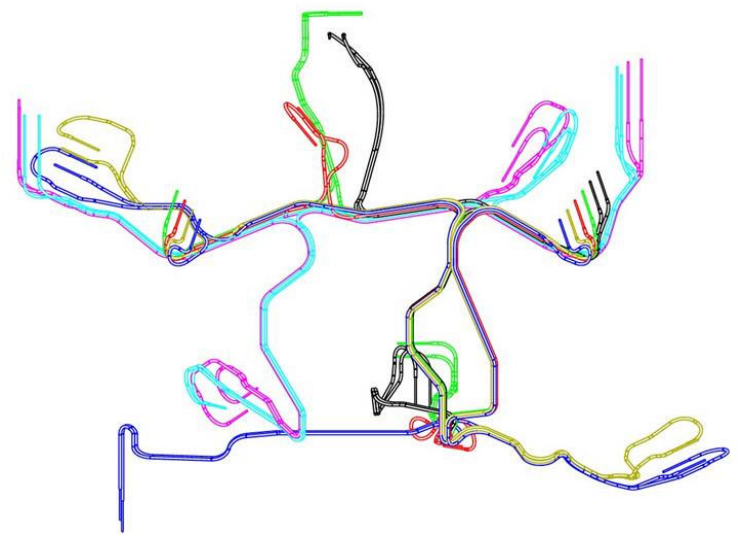

Figure 3: Schematic view of the bus-bar conductors for a single magnet module of Wendelstein 7-X. Bifilar arrangements are used to avoid stray fields from the bus-bars.

To connect the coils with each other (seven groups of 10 identical coils each in series) and with the current leads (which lead to the power supplies at ambient temperature), a superconducting bus-bar system is required, see Fig. 3. This system is being designed and manufactured by the research centre Jülich (FZJ, Germany) [11]. The same conductor is used as for the coils, and the routing is done for one non-planar and the planar coil groups in a bifilar way to reduce error fields from the bus-bar. The design of the bus-bar system has been finished, and manufacturing is well under way. The conductors for three modules have been delivered already, together with the corresponding supports (holders to fix the bus-bars to the support structure, and clamps to fix conductors to each other). The connection between the bus-bar system inside the cryostat (i.e. at about $4 \mathrm{~K}$ during operation and under vacuum) and the power supply lines outside the cryostat (i.e. at ambient temperature and pressure) requires 14 current leads that bridge the temperature and pressure transition. At Wendelstein 7-X we have the special situation that the power supplies are located directly below the stellarator. These current leads are mounted at the bottom of the device and have the cold end at top, and therefore require a special layout ("bottom-up"). A detail design for these current leads, able to carry $20 \mathrm{kA}$ each and using high temperature superconductor inserts, has been developed in collaboration with the research centre Karlsruhe, (FZK, Germany) [12]. A prototype current lead is being assembled now which will be tested under cryogenic conditions early in 2010.

\section{4) Cooling system}

The magnet system, including structure, is cooled down to $\approx 4 \mathrm{~K}$ and kept at that level throughout the different operation regimes by a highly flexible and efficient refrigeration plant with a cooling capacity equivalent to about $7 \mathrm{~kW}$ at $4.5 \mathrm{~K}$ [13, 14]. Components to be supplied by individually controllable circuits are the cable-in-conduit conductors (CICC), coil housings, the central support ring (CSR), current leads, and the thermal shield (Fig. 4). The refrigerator cold box is connected to the sub-cooler which in turn supplies via a $70 \mathrm{~m}$ long multiple transfer line the valve box (VB). In the VB the helium streams are further subdivided and distributed, again via transfer lines, to the components within the W7-X cryostat.
All the CICCs of the coils are supplied in parallel by loop 1 (Fig. 4) with supercritical $\mathrm{He}$ at around $4 \mathrm{~K}$ and 5 bar. The streams for the NPC and PLC sets can be controlled by valves within the VB. Distribution of the individual conductor flows within each coil set is left to the relatively high flow resistance of the cables. A filter within the VB protects the cable circuit from impurities. Another peculiarity of loop 1 is the direct supply from the Joule Thomson stream of the cold box. The circulation pump P1 is switched on if necessary, as expected during $3 \mathrm{~T}$ operation of the magnet system. A check valve (CV) protects the pump from the pressure wave in case of a quench.

Circuit 3 supplies the CSR and the coil housings also with $4 \mathrm{~K}-\mathrm{He}$, but at the lower pressure of $\approx 3.5$ bar. This circuit is sub-divided into 10 individual parallel CSR loops, one per halfmodule, and into 70 parallel loops for the coil housings. The flow resistances are balanced by one throttle valve within each of the 80 loops which is set only once except in case of abnormal component behaviour during operation. Part of the PLC housing return flows are taken for additional cooling of the current lead contacts. The circuit 3 return streams merge with those of loop 1 to the combined return circuit 2 . Distribution of the CSR and coil housing flow is controlled within the VB by a valve in the CSR return line. Circuit 3 is exclusively driven by circulator P3 (actually two pumps in parallel) which is also quench-protected by a check valve within the VB.

The HTSC current leads are supplied with $50 \mathrm{~K}$ helium mainly from the thermal shield circuit 5 which has a supply temperature around $50 \mathrm{~K}$ to $60 \mathrm{~K}$ at $14-18$ bar, depending on operation conditions, and is throttled down to a pressure of 2 - 3 bar. In order to guarantee $50 \mathrm{~K}$ at the CL inlet this flow is merged with a cold box He stream of $\approx 8 \mathrm{~K}$ and corresponding pressure. This mixed stream is warmed up within the CL to room temperature, then expanded to atmospheric pressure, and

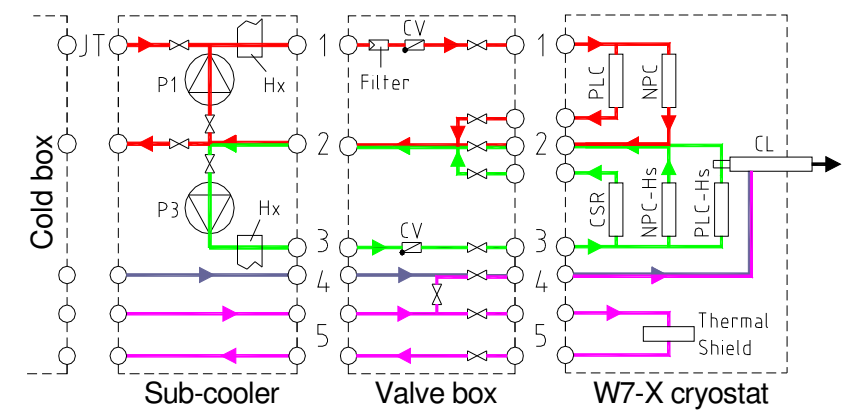

Figure 4: Principal magnet cooling scheme: 1 - conductor supply; 2 conductor, housing, structure, CL-auxiliary return; 3 - housing, structure, CL-auxiliary supply; 4 - CL main supply; 5 - thermal shield circuit; JT"Joule Thomson" (=main) stream from cold box; P1, P3 - circulation pumps; $H X$ - heat exchanger; $C V$ - check valve; PLC-planar coil; $N P C$ - non-planar coil; CSR - central support ring; NPC-Hs - housings of NPC; PLC-Hs - housings of PLC; CL-current leads.

finally fed back into the refrigerator compressor inlet stream. 
The heat exchangers ( $\mathrm{HX}$ in Fig. 4) downstream of the circulators reduce the supply helium temperature to minimally $3.4 \mathrm{~K}$, depending on W7-X operation requirements. "HX" represents three heat exchangers in a row which are connected to corresponding helium baths with minimal temperatures of $3.3 \mathrm{~K}, 3.8 \mathrm{~K}$ and $4.4 \mathrm{~K}$ at corresponding pressures of $1.2,0.66$ and 0.37 bar, respectively. Both the latter sub-atmospheric pressure levels are provided by one centrifugal cold compressor each within the cold box.

The sub-cooler is provided with interfaces to be equipped with another circulation pump circuit for the divertor cryo vacuum pumps. The corresponding circulator, transfer lines and valve box will be installed at a later state.

A special feature of the sub-cooler is the possibility to switch the cold-box JT stream to any one of the main cooling circuits, thus providing redundancy in case one of the circulators fails. And, if needed, the refrigeration power can be boosted up to $10 \mathrm{~kW}$ (at $4.5 \mathrm{~K}$ equivalent) for several hours by expanding liquid helium from the 10,000 LHe Tank into the $3.8 \mathrm{~K}$ bath within the sub-cooler. This way the loads can be levelled over a daily cycle.

All components of the refrigeration plant have been installed, and commissioning tests are running.

The conceptual design of the cryo-piping inside the cryostat has been finished and structural analyses have been performed [15]. The detail design has to be adapted for each module individually due to the very tight space situation inside the cryostat. Fabrication has started and manufacturing of the cryopipes for the first module has almost been finished.

\section{B. In-vessel components}

At the plasma edge, i.e. outside the closed flux surfaces, the magnetic configuration of $\mathrm{W} 7-\mathrm{X}$ forms a $\mathrm{m}=5$ island structure to be used as an island divertor to control the power and particle exhaust from Wendelstein 7-X [16]. According to the field structure described above, also the divertor will have a five-fold symmetry, i.e. it will be composed of 10 units, five on top and five on the bottom. Each unit consists of 12 target modules. This system has been designed for steady-state operation at the full ECRH-heating power of $10 \mathrm{MW}$ and for $10 \mathrm{~s}$ pulses of $15 \mathrm{MW}$ NBI heating power.

The full system of the in-vessel components [17] covers an area of $265 \mathrm{~m}^{2}$ and includes plasma-facing components as well as cryo pumps and correction coils to modify the extent and location of the islands on the target modules, summing up to a total mass of 33,8 tons.

The plasma facing components of the divertor are target modules, each consisting of 8 to 10 elements, (with a horizontal and a smaller vertical target plate) and the baffle modules. The highest thermally loaded parts are the actively cooled target modules with a surface area of $\sim 25 \mathrm{~m}^{2}$ to allow a wide range of magnetic configurations. These targets will experience high power fluxes of up to $10 \mathrm{MW} / \mathrm{m}^{2}$. The thermal loads are taken by flat target elements made of $\mathrm{CuCrZr}$ cooling structures with CFC-tiles bonded to its surface. A robust bonding technology has been developed in close cooperation with the supplier,
Plansee SE of Austria [18]. After a significant development effort, the technology was qualified in extensive high heat flux tests in the IPP GLADIS facility [19], demonstrating up to 10000 full power cycles on the elements [20].

The baffle, adjacent to the divertor targets, prevents the neutrals in the divertor chamber from escaping into the main plasma chamber and receives lower stationary power fluxes of up to $0.5 \mathrm{MW} / \mathrm{m}^{2}$. These components are built up of faceted actively cooled $\mathrm{CuCrZr}$ structures with grafite tiles clamped as plasma-facing armor.

In the divertor chamber, behind the target modules, 10 cryopumps are to be installed. Their design is based on the successful ASDEX Upgrade cryopump design.

Behind the baffle modules, 10 control coils will be installed. Manufactured by BNG, Germany, these components will allow to sweep the target points and to correct minor error fields.

For the remaining wall protection, two areas have to be distinguished which require different technical solutions. The wall protection is subjected to neutral particles and plasma radiation. In higher loaded areas, on the inboard side and closer to the plasma, heat shields with clamped carbon tiles, similar to the baffles, are installed. These are designed for a heat flux of up to $0.3 \mathrm{MW} / \mathrm{m}^{2}$. In the less loaded areas steel panels will be installed, that are designed for power fluxes of up to $0.2 \mathrm{MW} / \mathrm{m}^{2}$. These panels use a quilt technology to form the cooling circuits and are produced by an industrial team lead by DWE, Germany.

Supply of coolant for the components is made by pipework of $4.5 \mathrm{~km}$ length. The 170 individual circuits are arranged between the in vessel components and plasma vessel wall. Supply of the cooling water into the plasma vessel is achieved by 80 plug-ins in the supply ports. They connect the external supply lines with the internal pipe work. Fig. 5 shows a fully equipped cooling circuit prototype during installation into a wooden plasma vessel segment mock up

Some diagnostic ports will be protected by panel-type port liners and the ports for NBI and diagnostic injector will be protected by port liners, using a technology similar to the baffles.

Design and manufacturing of the in vessel components is well under way. The control coils were delivered to Greifswald in 2008 . Over $60 \%$ of the wall protection elements have been manufactured and assembly of the first cooling circuits has started.

Work on an inertially cooled test divertor [21], to be installed in the first experimental phase, is running and design of the high heat flux divertor modules is going on in parallel. A prototype of a target module was tested successfully and has verified the layout. The parts of the cryopumps are available, although the pumps will be installed only later, for the second experimental phase.

\section{ECRH-system}




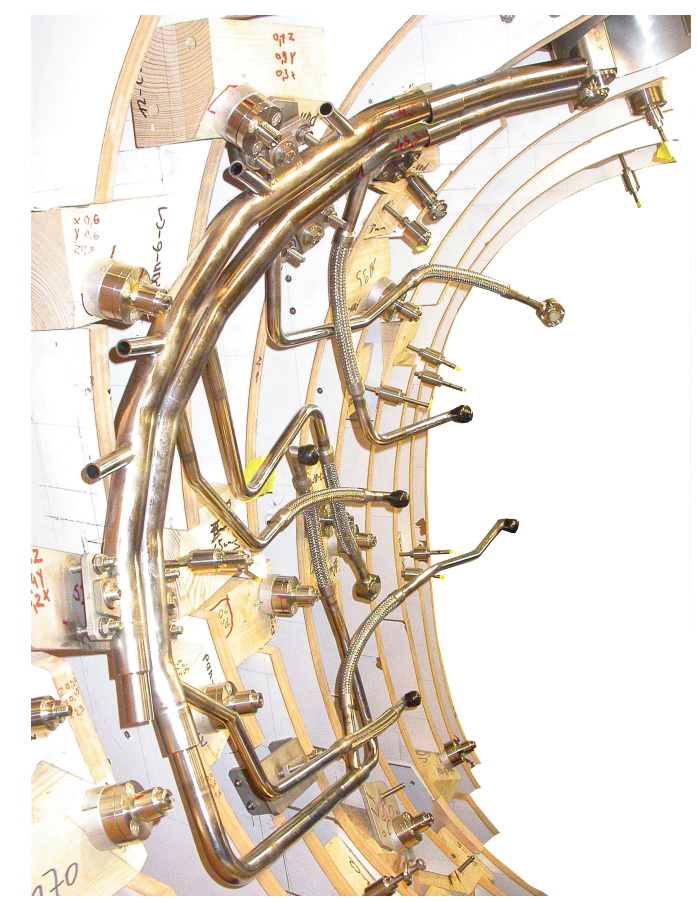

Figure 5: Prototype cooling circuit during installation in the wooden plasma vessel mock-up.

The Electron Cyclotron Resonance Heating (ECRH) system for W7-X is being developed and built by the German research centre Karlsruhe (FZK) as a joint project with IPP and IPF Stuttgart in the 'Project Microwave Heating for W7-X' (PMW) being responsible for the entire ECRH system for W7-X. This ECRH system [22] has been designed for a microwave power of $10 \mathrm{MW}$ in continuous wave $(\mathrm{CW})$ operation $(30 \mathrm{~min})$ at $140 \mathrm{GHz}$, which is resonant with the W7-X magnetic field of $2.5 \mathrm{~T}$. It will consist of ten Gyrotrons with $1 \mathrm{MW}$ power each, a low loss quasi-optical transmission line, and a versatile invessel launching system. It will support also operation of $\mathrm{W} 7-\mathrm{X}$ at reduced magnetic field, because the gyrotrons can be tuned to $103.6 \mathrm{GHz}$ radiation emission with about half the output power. This is of particular importance during the commissioning phase of $\mathrm{W} 7-\mathrm{X}$ and for confinement studies.

\section{1) The W7-X Gyrotrons}

The development of steady-state gyrotrons with output power in the megawatt range still is a subject of worldwide R\&D efforts, mainly driven by the needs of W7-X and ITER.

The development of the W7-X gyrotron started in 1998 in cooperation with companies in the EU and in the US. The design approach chosen for this development includes single stage collector depression to enhance the efficiency and to relax the collector loading. To simplify the design, this gyrotron has no control anode. The collector is at ground potential, the cathode voltage has negative polarity and the depression voltage (cavity and body) is positive. The output vacuum window uses a single (water-cooled) disk of chemicalvapor-deposited diamond with a diameter of $106 \mathrm{~mm}$, a window aperture of $88 \mathrm{~mm}$ and a thickness of $1.8 \mathrm{~mm}$, corresponding to four half-wavelengths.
After the successful completion of the gyrotron R\&D in EU [23], the first out of seven series gyrotrons (SN1) had been delivered by Thales Electron Devices (TED) in 2005, see Fig. 6. In the same year also the prototype gyrotron from CPI has been delivered [24]. Both gyrotrons have been tested at FZK and IPP. All the specifications were met and no specific limitations were observed during the acceptance test. Both gyrotrons were operated for 30 minutes at an output power of $900 \mathrm{~kW}$ (CPI-gyrotron) and $920 \mathrm{~kW}$ (TED-gyrotron), respectively, measured after transmission over $25 \mathrm{~m}$. In order to keep the warranty, the SN1 gyrotron has been sealed while the two prototype gyrotrons were routinely used for experiments. The next series gyrotrons showed, however, a different behaviour with respect to parasitic oscillations excited in the beam tunnel region, resulting in an excessive heating of the beam tunnel components. This has limited the steady-state output power of these gyrotrons. Therefore, it was agreed with TED to stop the series production until mid 2009 and focus the activities on a coordinated beam-tunnel $R \& D$ to overcome the problems and to arrive at a more robust beam tunnel, which suppresses the excitation of parasitic oscillations more efficiently. This development is running smoothly.

\section{2) Transmission System}

The transmission line consists of single-beam waveguide (SBWG) and multi-beam waveguide (MBWG) elements. For each gyrotron, a beam conditioning assembly of five singlebeam mirrors is used. Two of these mirrors match the gyrotron output to a Gaussian beam with the correct beam parameters, two others are used to set the appropriate polarization needed for optimum absorption of the radiation in the plasma. A fifth mirror directs the beam to a plane mirror array, the beam combining optics, which is situated at the input plane of a multi-beam waveguide. This MBWG is designed to transmit up

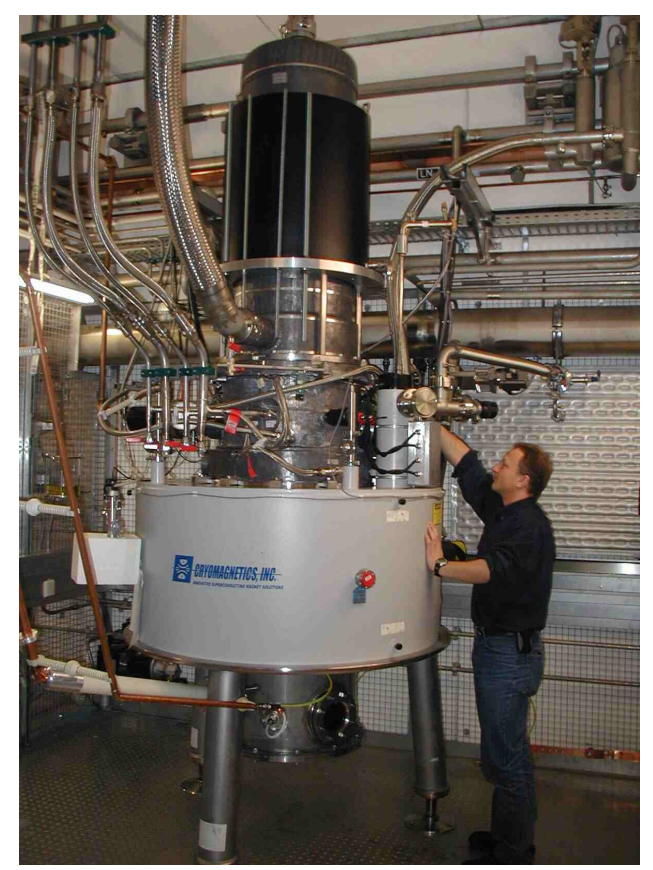

Figure 6: First series gyrotron at IPP 
to seven beams (five $140 \mathrm{GHz}$ beams plus additional spare channels) from the gyrotron area (entrance plane) to the stellarator hall (exit plane). At the output plane of the MBWG, a mirror array separates the beams again and distributes them via CVD-diamond vacuum barrier windows to individually movable antennas (launchers) in the torus. The long distance transmission is provided by two symmetrically arranged MBWGs. Long distance transmission has been simulated and tested by transmitting the high power beams half way in forward direction and then back via the reflectors to the dummy load. Total losses of about $3 \%$ were measured over a total length of about $40 \mathrm{~m}$. These measured total losses are in good agreement with calculations and previous low power measurements. This result confirms the high quality of the quasi-optical concept for high power, long distance transmission.

\section{3) HV-systems}

For the operation of gyrotrons with depressed collector, a precisely controlled beam acceleration voltage is necessary, which is supplied by the body-voltage modulator. The beam current of the gyrotrons is controlled by the cathode heater supply, which is on cathode potential (about $-55 \mathrm{kV}$ ). In case of arcing inside the gyrotron, a thyratron crowbar protects the tubes from being damaged. The body-voltage modulators and the protection units were designed by and built at IPF Stuttgart. All ten systems are now installed at $\mathrm{W} 7-\mathrm{X}$ and are ready for operation. An additional protection unit was integrated to enable the exact location of the source of a fault in case of malfunction of the gyrotron.

\section{4) In-vessel-components}

The ECRH System for W7-X must provide plasma start-up and operation at full performance. The plasma start-up will be initiated by ECRH at the resonant magnetic field strength for both operating frequencies at 105 and $140 \mathrm{GHz}$. The control of the rotational transform profile during the density build-up requires a highly flexible launching and power control system. As soon as the plasma density approaches the X2 cut-off density, a well-controlled transition from the strongly absorbed second harmonic extraordinary mode (X2) to a multi-pass second harmonic ordinary mode $(\mathrm{O} 2)$ heating scenario must be performed. The key elements are the four front steering ECRHantennas in the outboard midplane ports. All parts of the antennas are expected to experience a high power loading by either direct microwave irradiation, in particular the mirrors and diamond vacuum windows, or by strong microwave stray radiation at the screening and support elements. Therefore all components require active cooling and/or screening. The design of the antennas was frozen after successful tests of several critical subcomponents. Two out of four plug-in antennas modules have been completed and tests are presently performed.

\section{Diagnostics}

The step being taken in W7-X towards quasi-steady state operation poses a significant number of new challenges regarding the development of diagnostics [25]. With $10 \mathrm{MW}$ of ECRH heating power being available for pulses of up to $30 \mathrm{~min}$ duration, and the duration of the discharge only being limited by the heat capacity of the cooling water reservoir, all in-vessel diagnostic components are being exposed quasi-continuously to thermal loads of $50-100 \mathrm{~kW} / \mathrm{m}^{2}$ from radiation alone [26]. Some diagnostics, like the soft x-ray multi camera tomography system (XMCTS) and the in-vessel diamagnetic loops which are mounted onto the plasma vessel wall, need in addition to be protected against convective loads of up to $500 \mathrm{~kW} / \mathrm{m}^{2}$ by an actively cooled heat shield [27]. The high heat loads make it necessary to develop actively water cooled plasma facing optical components like windows [28] and mirrors as well as water cooled shutters [27] to protect some of these components during long pulse operation from getting severely contaminated with carbon deposits. Furthermore, in-situ cleaning techniques, like heating the optical components to elevated temperatures over night or during weekends $[25,26]$ and in-situ intensity calibration techniques have to be developed. For the in-vessel retro-reflectors being developed for the multi-channel interferometer and the polarimeter it is presently not known whether they will be mostly affected by deposition or erosion. A rather similar situation exists for many plasma facing optical components in ITER. For this reason, in Wendelstein 7-X the most erosion stable material, Molybdenum, is going to be used.

One of the most critical diagnostic items for steady state operation of W7-X will be the combined infrared/visible divertor observation endoscopes $[29,30]$ which need to ensure that none of the targets of the 10 discrete divertor modules are ever exposed to excess heat loads which could easily destroy them. These systems are designed such that the entrance pupil of their optics is lying inside an $\sim 5 \mathrm{~mm}$ observation pinhole inside a water cooled stainless steel plate facing the plasma. In this way the transmission losses of the first mirror by the buildup of soft a:C-H layers can be minimized for such systems which, for machine protection reasons, need to be operable at all times without any interruption, i.e. no shutter may be closed during plasma operation. As has been observed in Tore Supra, redeposited carbon material across the divertor surfaces and in particular near the stress relieving cuts into the divertor target material can cause major problems for the derivation of the carbon tile temperatures near the interlayer to the $\mathrm{CuCrZr}$ cooling structure, which at no time may exceed $475^{\circ} \mathrm{C}$. The required spatial resolution of the IR system of less than $10 \mathrm{~mm}$ across each $4 \mathrm{~m}$ long divertor can only be achieved by using two micro-bolometer cameras per system. This is due to the high diffraction limit in the wavelength region of $\sim 10 \mu \mathrm{m}$.

An area in which basically no prior knowledge from other fusion devices exists, is the shielding of various diagnostics, in particular during high density operation, from high levels of ECRH stray radiation. Near the cut-off densities of the X2 mode $\left(1.2510^{20} \mathrm{~m}^{-3}\right.$ ) and during $\mathrm{O} 2$ mode (up to $2.510^{20} \mathrm{~m}^{-3}$ ) and $\mathrm{OXB}$ mode operation, ECRH stray radiation levels vary toroidally from $200 \mathrm{~kW} / \mathrm{m}^{2}$ in the launching plane to about $50 \mathrm{~kW} / \mathrm{m}^{2}$ at the opposite side of the torus. Tests in our specially set up ECRH stray radiation test chamber have already shown that great care needs to be taken, e.g., to properly shield the in-vessel magnetic diagnostic components to prevent overheating of the wires of the diamagnetic loops, the Rogowski or the Mirnov coils and any other in-vessel cabling. Shielding wire meshes were found not to be suitable because they are heated to high temperatures by the stray radiation. Also observation windows as well as many types of 
ceramics absorb significant amounts of stray radiation making shielding or efficient cooling essential.

It can be seen from the above that a major part of any diagnostic development for quasi-continuously operating nuclear fusion devices needs to be invested into making the diagnostics fit to survive in the rather hostile environment.

\section{E. Control system}

Steady state operation of high performance fusion plasmas can be enabled only by an intelligent control system that can drive the plasma into favorable states while taking care for technical load limits of first wall and divertor components. In steady state reactor relevant scenarios, control loops with very long time constants, like $\mathrm{L} / \mathrm{R}$ or thermal time constants, pose a challenge for the plasma control [31]. The Wendelstein 7-X system comprises of several major components, the steady state data acquisition system, the device control system with time variable configuration parameters, and an automated data analysis system that allows for the integration of theory models. A major requirement on data acquisition and control system is the permanent full documentation of discharges and monitoring of the machine states, the latter running 24 hours a day.

The steady state data acquisition system [32] has to treat a permanent data flow with transfer rates in the order of several GByte/s which is demanding even for modern network and storage technologies. It stores the data directly and in a well structured format into an object database. The total amount of data per long pulse discharge is expected to be in the order of several TByte. Furthermore, a significant fraction of the storage is required for the inter discharge data archiving of device state monitoring.

The control system foreseen for $\mathrm{W} 7-\mathrm{X}$ has to provide three different systems, the safety control system, operational management, and real time control of the plasma [33]. It is hierarchically structured in a way that each local component, such as coil power supplies, heating and cooling systems, diagnostics and so on, has its own Local Control System (LCS). For commissioning and tests, these LCS are operated

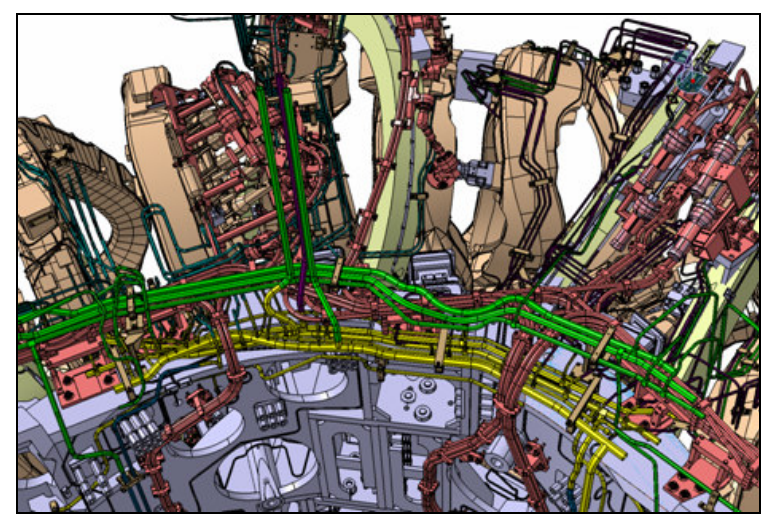

Figure 7: $C A D$-view of the central support ring with some coils and bus-bars (brown) and cryo-pipes (yellow, green and black), illustrating the very tight assembly space inside the cryostat. autonomously. For operation of W7-X, all these components will be controlled by the Central Control System (CCS), which coordinates the activities of the subordinated LCS [33]. LCS and CCS consist of an operational management and a real time control system, the latter being supervised by the operational management itself. The real time plasma control provides control states in temporal segments containing control parameters for LCS and CCS, which can be varied in a flexible way during the discharge. By this complete discharge scans become feasible in single experiment runs. The safety system works independently and consists again of local units for each component, and a central safety system controlling the safety of the full system.

The analysis and modeling framework, required for the plasma physics driven control, will be based on service oriented architectures in which plasma models and data analysis components are exposed as services running on distributed computing nodes. At present, grid computing middleware is under investigation with respect to suitability, quality of service, scalability and other requirements. It is planned to use this middleware for the coupling between distributed high performance computing and the real time control system.

This data acquisition and control system for $\mathrm{W} 7-\mathrm{X}$ is under development and, as a system test, a first prototype is currently operated on the small WEGA stellarator in Greifswald [34]. The further development of the W7-X control system will be based on the experiences from this prototype.

\section{STATUS OF CONSTRUCTION}

Development and manufacturing of most of the components of the basic device have been finished, except for those components where the detail design and fabrication run in parallel to the assembly, i.e. the components in the cryostat like cryo-piping and thermal insulation of the outer vessel. Therefore the main focus on construction of Wendelstein 7-X has shifted from component manufacturing to the assembly of the device, to be described in the following paragraphs.

At present, four out of the five modules are in the assembly process which is handled on a sequence of assembly rigs [35]. On the first of these modules which is presently on assembly rig III, the bus-bar conductors have been assembled and the last cryo-pipes are presently being mounted. Due to the narrow installation space, mentioned above, design of these pipes has required several iteration cycles of design and collision control, making this process even more time-consuming than expected. Fig. 7 illustrates the narrow assembly space using the example of the central support ring with bus-bars and cryo-pipes. At present, the joints between the bus-bars and coil conductors are assembled.

The second module is presently being equipped with the first cryo-pipes on a temporary assembly rig, while on rig II the half-modules of the third module are assembled. The halfmodules of the central support ring have been connected with shear bolts, the vacuum vessel sectors have been welded, and the inter-coil supports have been completed. The half-modules of the fourth module are being assembled on a routine basis. 
At present, the first module of the outer vessel [36] is being equipped with the thermal insulation. Due to the very tight space inside this cryostat, the detailed design of the thermal insulation had to be subjected to an iterative collision control and design process, thereby delaying manufacturing and assembly. Therefore, the installation of the first module into the outer vessel had to be shifted by about two months. In spring of 2010 , assembly of the first ports is scheduled to start.

\section{SUMMARY AND OUTLOOK}

For construction of the steady-state stellarator Wendelstein 7-X several components had to be further developed with regard to the steady state requirements. These developments have been concluded successfully. As of now, the main tasks of the project are concentrated on the assembly of the device. Some of the assembly steps are performed on a routine basis by now, but there are still many assembly steps ahead which have been developed, but have not yet been performed. Therefore the schedule bears still some uncertainty for the technical risks, especially concerning these new processes.

The general schedule for construction of Wendelstein 7-X foresees conclusion of assembly and start of commissioning for summer 2014.

[1] J. Nührenberg, W. Lotz, P. Merkel, C. Nührenberg, U. Schwenn, E. Strumberger, T. Hayashi, Overview on Wendelstein 7-X Theory, Trans. Fusion Techn. 27, 71 (1995).

[2] S. Gori, W. Lotz and J. Nührenberg, Quasi-isodynamic Stellarators, ISPP 17, Theory of Fusion Plasmas, SIF, Bologna 1996, p. 335

[3] H.-S. Bosch, Wendelstein 7-X - a technology step towards Demo, Plasma and Fusion Research (2009), in press.

[4] C. Sborchia, J. Baldzuhn, J.H. Feist, K. Riße, T. Rummel, H. Viebke and M. Wanner; Progress in the Design, Manufacture and Testing of the W7-X Superconducting Magnets, IEEE Trans. Appl. Supercond. 16, 848 (2006).

[5] H. Scheller, H.P. Langenberg, M. Kühnberg, J. Baldzuhn, B. PetersenZarling, D. Gustke and H. Fillunger; Paschen Testing on W7-X Coils and Components in the BNN Test Facility, IEEE Trans. Appl. Supercond. 16, 759 (2006).

[6] J. Baldzuhn, Cold Test of the Superconducting Coils for the Stellarator for W7-X, IEEE Trans. Appl. Supercond. 18, 509 (2008).

[7] H. Viebke, T. Rummel, K. Riße, R. Schroeder and R. Winter, Fabrication of the planar coils for Wendelstein 7-X, Fusion Eng. Design 75-79, 201 (2005)

[8] A. Benito, D. Goitia, E. Casado, M. Andreres, E. Vázquez, M. Fajardo, C. Palacios, A, Cardella, D. Pilopp, L. Giodarno and G. Di Bartolo; Manufacturing of the coil support structure for W7-X, Fusion Eng. Design 82, 1579 (2007).

[9] A. Dudek, A. Benndorf, V. Bykov, S. Cardella, C. Damiani, A. Dübner, W. Dänner, M. Gasparotto, T. Höschen and G. Matern, Tests of critical bolted connections of the Wendelstein 7-X coils, Fusion Eng. Design 82, 1500 (2007).

[10] J. Reich et al., Manufacture of Inter-Coil-Support-Elements of the W7-X Magnet System, $22^{\text {th }}$ IEEE Symp. Fusion Eng., Albuquerque, 2007.

[11] M. Sauer, B. Giesen, A. Charl, R. Schick, S. Brons, A. Panin, H. Reimer, W. Tretter, M. Schumacher, R. Caspers and W. Schalt, Design and construction of the superconducting bus system for the stellarator $W 7-X$, Fusion Eng. Design 82, 1460 (2007).

[12] W. H. Fietz, R. Heller, A. Kienzler and R. Lietzow, High temperature superconductor current leads for Wendelstein 7-X and JT-60SA, , IEEE Trans. Supercond. (2009) in press.

[13] F. Schauer et al., KI Luft- und Kaeltetechnik 4, 124 (2005).
[14] A. Kuendig, C. P. Dhard, S. Raatz, H. Bau, Progress Report of the CryoPlants for Wendelstein-7X, Proc. 22nd Int. Cryog. Eng. Conf., Seoul, Korea (2008).

[15] A. Dübner, D. Zacharias, M. Nagel, V. Bykov, F. Schauer, and M. Ihrke, Structural analysis of the W7-X cryogenic pipe system, Fusion Eng. Design 84, 684 (2009).

[16] H. Renner, D. Sharma, J. Kißlinger, J. Boscary, H. Grote, R. Schneider, Physical Aspects and Design of the Wendelstein 7-X Divertor, Fusion Science Techn. 46, 318 (2004).

[17] R. Stadler, A. Vorköper, J. Boscary, A. Cardella, F. Hurd, C. Li et al., The in-vessel Components of the Experiment WENDELSTEIN 7-X, Fusion Eng. Des. 84, 305 (2009).

[18] J. Boscary, H. Greuner, T. Friedrich, H. Traxler, B. Mendelevitch, B. Böswirth et.al., Pre-series and testing route for the serial fabrication of W7-X target elements, Fusion Eng. Des. 84, 497 (2009).

[19] H. Greuner et al., High Heat Flux Facility GLADIS: Operational Characteristics and Results of W7-X Pre-Series target Tests, J. Nucl. Mat. 367-377,1444 (2007).

[20] J. Boscary et al., Results of the Examinations of the W7-X preseries target elements, Fusion Eng. Design 82, 1634 (2007).

[21] A. Peacock, H. Greuner, F. Hurd, J. Kißlinger, R. König, B. Mendelevitch et al., Progress in the design and development of a test divertor (TDU) for the start of W7-X operation, Fusion Eng. Des. 84, 1475 (2009).

[22] V. Erckmann et al., Electron heating for W7-X: physics and technology, Fusion Science Techn. 52, 291 (2007).

[23] G. Dammertz, S. Alberti, A. Arnold, E. Borie, V. Erckmann et al., Development of a 140-GHz 1-MW continuous wave gyrotron for the W7$X$ stellarator, IEEE Trans. Plasma Sci. 30, 808 (2002).

[24] K. Felch, M. Blank, P. Borchard, P. Calahan, S. Cauffman, T. S. Chu and H. Jory, Recent ITER-relevant gyrotron tests, J. Physics Conf. Series 25, 13 (2005).

[25] H.-J. Hartfuss, R. König and A. Werner, Diagnostics for steady state plasmas, Plasma Phys. Control. Fusion 48, R83 (2006).

[26] T. Eich and A. Werner, Numerical Studies on Radiative Heat Loads to Plasma-Facing Components for the W7-X Stellarator, Fusion Science and Technology 53, 761 (2008).

[27] R. König, Diagnostic Developments for Quasi-Continuous Operation of the Wendelstein 7-X Stellarator, Rev. Sci. Instr. 79, 10F337 (2008).

[28] R. König, K. Grosser, D. Hildebrandt, O,V. Ogorodnikova, C. v. Sehren and T. Klinger, Development of an actively cooled periscope head suitable for divertor bservation during quasi-continuous operation of the W7-X stellarator, Fusion Eng. Design 74, 751 (2005).

[29] J. Cantarini, Optical Design Study of an Infrared Visible Viewing System for Wendelstein 7-X Divertor Observation Control, Rev. Sc. Instrum. 79, 10F513 (2008).

[30] R. König, D, Hildebrandt, T. Hübner, F. Klinkhamer, K. Moddemeijer and W. Vliegenhart, Optical design study for divertor observation at the stellarator W7-X, Rev. Sc. Instrum. 77, 10F121 (2006).

[31] A. Werner, A. Dinklage, G. Kühner, H. Maaßberg, J. Schacht, J. Svensson et al., Integrated Software Development for Wendelstein 7-X, FT/P7-6, 21st IAEA Fusion Energy Conference, Chengdu, 2006.

[32] P. Heimann et al., Status report on the development of the data acquisition system of Wendelstein7-X, Fusion Eng. Design 71, 219 (2004).

[33] J. Schacht et al., Overview and status of the control system of Wendelstein 7-X, Fusion Eng. Design 82, 988 (2007).

[34] J. Schacht et al., Overview and status of the prototype project for Wendelstein 7-X control system, Fusion Eng. Design 84, 1723 (2009).

[35] L. Wegener, Status of Wendelstein 7-X construction, Fusion Eng. Design 84, 106 (2009).

[36] T. Koppe, A. Cardella, J. Reich, B. Missal, B. Hein, R. Krause et al., Manufacturing and Assembly Status of Main Components of Wendelstein 7-X Cryostat, 23 ${ }^{\text {rd }}$ IEEE Symp. Fusion Eng., San Diego, 2009. 